\title{
Application of FPA and ANOVA in the optimization of liquid flow control process
}

\author{
Pijush Dutta ${ }^{1 *}$, Sudip Mandal ${ }^{1}$, Asok Kumar $^{2}$ \\ ${ }^{1}$ Dept. of Electronic \& Communication Engineering, Global Institute of Mangement \& Technology, Nadia, West Bengal \\ 741102, India \\ ${ }^{2}$ Dept. of Electronic \& Communication Engineering, MCKV Institute of Engineering, Liluha, Howrah 711204, India
}

Corresponding Author Email: pijushdutta009@gmail.com

https://doi.org/10.18280/rces.050102

Received: 6 January 2018

Accepted: 23 March 2018

\section{Keywords:}

liquid flow process, optimization, ANOVA, FPA.

\begin{abstract}
In process industry liquid flowrate is one of the important variable which need to be controlled in a process to obtain the better quality and reduce the cost of production. As the liquid Flow rate in a process industry depends upon a number of parameter so the process will give the unexpected output as it is caused by the improper setting of parameters. The improper parameter settings could threaten the processes. In this paper, we utilize the Flower Pollination Algorithm (FPA) methods and ANOVA to obtain the optimum conditions of a flowrate in a process industry and to gain the percentage of contributions of each parameter by. A verification test was carried out to inspect the optimum output among the ANOVA \& FPA. For generating the objective function 120 sets of data is used in ANOVA while 18 sets of data are used for the verification purpose.
\end{abstract}

\section{INTRODUCTION}

In most of the industrial applications, there is a need to calculate the inputs to a process that will drive its outputs in a desired way and thus achieve some optimum (desired) goal. In such applications, a mathematical input-output model for the process is usually derived. The model could be based on the physical phenomena or available historical input-output data. Once the model is developed, mathematical techniques can be applied to determine the inputs to the process that will satisfy a certain given criterion. Combustion engines [21-24], twostage combustor burning ethylene (doped with ammonia) in air [25], catalytic distillation [26] and desulphurization of hot metal and steel [27] those are the industrial process where the modelling and optimization research have been conducted. The developed optimization algorithm is tested on a novel flow thermal sensor whose inputs are the flow velocity and fluid temperature and output is the voltage measurement. [29] Present thermal flow sensor has a high sensitivity at low flow rates because of the non-linear transfer function of the sensor which makes the device especially suitable for very low flow rates measurements. From the experimental set up provides 5 different variables where four inputs (sensor output, pipe diameter, liquid conductivity, liquid viscosity) \& single output, flow rate. An objective function is constructed with help of the four parameters which makes this process nonlinear.

\section{LITERATURE REVIEW}

Liquid flow optimization is the one of the process where the optimized flow in a process plant can be achieved from a set of value of the process parameters. In [31] an optimized ANN model is designed so that it approximation \& calibration the datasets which determines the velocity of the gas in a pipe if the thermal flow sensor voltage and the fluid temperature are known. Optimized ANN minimizing an objective function that measures the difference between the neural net approximated voltage and its desired value. In [32] described a Fuzzy Temperature compensation scheme (FTCS) for hot wire mass airflow (MAF) sensor used to compensate the measurement error occurred by using Sugeno type FIS for temperature of $60 \mathrm{C}-100 \mathrm{C}$. The proposed fuzzy compensation scheme in MAF is verified with the estimation error within only $\pm 1 \%$ over full scale value. The output of the thermal sensor is increase with wire temperature that is the time constant of the heated wire which is again related to the velocity of flow. At very low flow velocities the response is determined by the time constant of the wire while at high velocities the response is almost like a constant current hotwire anemometer. A Fuzzy model is implemented which approximate the calibration data for the sensor and shows the better accuracy. In [30] a thermal flow sensor designed which has a high sensitivity at low flow rates because of the non-linear transfer function of the sensor which makes the device especially suitable for very low flow rates measurements. The sensitivity of the flow sensor is approximately $0.3 \%$ at low flow velocities and it increases with velocity to reach 3\% at high velocities. In [33] a Fuzzy Temperature compensation scheme (FTCS) is developed for hot wire mass airflow (MAF) sensor to compensate the error. In this paper a Sugeno type FIS is used for the temperature variation of $60 \mathrm{C}-100 \mathrm{C}$. It verify the performance of the proposed hot wire MAF sensor temperature compensation schem. The proposed fuzzy compensation scheme is verified that estimation error lies within $\pm 1 \%$ over full scale value.

Real-world optimization problems are very complex and challenging to solve, and many applications have to deal with these problems. To solve such problems, approximate optimization algorithms have to be used, though there is no guarantee that the optimal solution can be obtained [1]. Over the last few decades optimization algorithms have been applied in extensive numbers of difficult problems. Several 
nature-inspired algorithms have been developed over the last few years by the scientific community [2] [4] [5]. The reproduction of flower is achieved via the pollination process. Flower pollination can be described as the Metaheuristic processes where the pollen distributed through a wide range of pollinators such as insects, birds, bats and some other animals [7].The purpose of this study was to find the optimum conditions of the process since they were unknown.The application of FPA \& ANOVA method is expected to help reduce the amount of time for which the liquid flow process produce the optimum output.

\section{EXPERIMETAL PROCEDURE}

The experiments were carried out on process control instrument to optimize the liquid flow. In these experiments, PTC thermistor based Anemometer flow sensor was selected as a transducer placed at a diametrical plane of a PVC pipe. In this research there five input variables among them levels of four input variable factors viz. Sensor output, pipe diameter, water density \&water viscosity and their levels are shown in table 1 are also the degree of main factors and interaction among them are studied to evaluate the process output that is flow rate. Same type anemometer flow rate sensor was carried out in the component in each experiment. Tables 2 shows experimental readings for the liquid flow depends upon the different level of the input process variables.

Table 1. Range \& parameter

\begin{tabular}{|c|c|c|c|c|c|c|}
\hline \multirow[b]{2}{*}{ Para-meters } & \multirow{2}{*}{$\begin{array}{c}\text { Output } \\
\text { Flow } \\
\text { rate }\left(\mathrm{m}^{3} / \mathrm{s}\right)\end{array}$} & \multicolumn{5}{|c|}{ Input } \\
\hline & & Diameter (m) & Density $\left(\mathrm{kg} / \mathrm{m}^{3}\right)$ & Conductivity (s/m) & Viscosity (Pa.S) & $\begin{array}{l}\text { Sensor } \\
\text { output (v) }\end{array}$ \\
\hline Min & 0 & 0.020 & 0.995 & 0.6065 & 0.7254 & 0.210 \\
\hline Max & 0.0096 & 0.030 & 0.998 & 0.6222 & 0.8982 & 0.287 \\
\hline
\end{tabular}

Table 2. Test data for control parameters \& their level

\begin{tabular}{|c|c|c|c|c|}
\hline Sensor output(volt) & $\begin{array}{c}\text { Diameter } \\
(\mathbf{m})\end{array}$ & $\begin{array}{c}\text { Viscosity } \\
\text { (Pa.S) }\end{array}$ & $\begin{array}{c}\text { Conductivity } \\
(\mathbf{S} / \mathbf{m})\end{array}$ & Flow $\operatorname{rate}\left(\mathbf{m}^{3} / \mathbf{s}\right)$ \\
\hline 0.218 & 0.024 & 0.6065 & 0.8982 & 0.0008 \\
\hline 0.221 & 0.025 & 0.615 & 0.7797 & 0.0008 \\
\hline 0.225 & 0.02 & 0.61 & 0.8982 & 0.0016 \\
\hline 0.232 & 0.025 & 0.597 & 0.7797 & 0.0016 \\
\hline 0.234 & 0.02 & 0.615 & 0.8982 & 0.0024 \\
\hline 0.237 & 0.027 & 0.622 & 0.7797 & 0.0024 \\
\hline 0.238 & 0.03 & 0.606 & 0.7254 & 0.0024 \\
\hline 0.239 & 0.025 & 0.615 & 0.8982 & 0.0032 \\
\hline 0.241 & 0.027 & 0.622 & 0.7797 & 0.0032 \\
\hline 0.245 & 0.024 & 0.606 & 0.7254 & 0.0032 \\
\hline 0.247 & 0.024 & 0.615 & 0.8982 & 0.004 \\
\hline 0.247 & 0.025 & 0.622 & 0.7797 & 0.004 \\
\hline 0.25 & 0.025 & 0.606 & 0.7254 & 0.0048 \\
\hline 0.256 & 0.025 & 0.615 & 0.8982 & 0.0048 \\
\hline 0.254 & 0.024 & 0.622 & 0.7797 & 0.0056 \\
\hline 0.259 & 0.03 & 0.6065 & 0.7254 & 0.0064 \\
\hline 0.265 & 0.027 & 0.622 & 0.7797 & 0.0064 \\
\hline
\end{tabular}

\section{RESULT ANALYSIS}

\subsection{ANOVA approach}

Table 3. characteristics of ANOVA

\begin{tabular}{|l|l|c|c|c|c|}
\hline & DF & \multicolumn{1}{|c|}{ SS } & MS & F & Significance F \\
\hline Regression & 4 & 34.11306 & 8.528266 & 39.1369 & $6.8378 \mathrm{E}-20$ \\
\hline Residual & 103 & 22.44453 & 0.217908 & & \\
\hline Total & 107 & 56.55760 & & & \\
\hline
\end{tabular}

ANOVA is a statistically decision-making tool to detect differences in the average performance and helps testing the significance of all main factors. ANOVA method was utilized to understand the percentage of contribution of each parameter [29] as well as determine the co efficient of a multivariable equation. Table 2 shows that how all the parameters affect the in the liquid flow process. When F-ratio is greater than F-table then the hypothesis null is rejected. By comparing F-table
$(\mathrm{F} 0.05,2,18)=3.55$ to $\mathrm{F}$ ratios with the level of significance $\alpha=5 \%$, we found that All F ratios above are greater than 3.55 therefore, all factors are affecting the responses. Statistically, there is a tool called an F test, named after Fisher [15], to see which design parameters a significant effect on the quality characteristic have, increases the current density in the gap with the consequent rapid anodic dissolution. traditionally used to determine the significance of a factor. The P-value 
reports the significance level (suitable and unsuitable) in Table3. Percent (\%) is defined as the significance rate of the process parameters on the metal removal rate. In the analysis, the F-ratio is a ratio of the mean square error to the residual error. First column of the table 3 indicates the co efficient of the multivariable objective function by considering the 108 number of datasets.

From the table we get the objective function of liquid flow rate $y(1)$ in terms of sensor output(1), pipe diameter $\mathrm{x}(2)$, liquid conductivity $\mathrm{x}(3) \&$ liquid viscosity $\mathrm{x}(4)$ expressed in $y(1)=\left(0.350099 * 10^{\wedge}-3\right) *\left(x(1)^{\wedge} 14.20\right)^{*}\left(x(2)^{\wedge}-.37947\right) *\left(x(3)^{\wedge}-\right.$ $12.94) *\left(x(4)^{\wedge} 2.940\right)$

4.1.1 Verification

The purpose of the verification test was to confirm the validity of the predicted value. In this purpose MATLAB is utilized to predict the result of the given process with the optimum settings that obtained by using ANOVA. Total error is $6.5656 \mathrm{e}-04(\mathrm{fmin})$ for the difference between predicted output \& actual output.

Table 4. Coefficient of variables

\begin{tabular}{|c|c|c|c|c|c|c|}
\hline & Coefficients & Standard Error & t Stat & P-value & Lower 95\% & Upper 95\% \\
\hline Intercept & -6.67100 & 11.323 & 0.5891 & 0.55701 & -29.12 & 15.787 \\
\hline X Variable 1 & 14.204 & 1.1535 & 12.313 & $5.769 \mathrm{E}-22$ & 11.917 & 16.492 \\
\hline X Variable 2 & -4.3187 & 0.4571 & 9.4471 & $1.254 \mathrm{E}-15$ & -5.2253 & -3.4120 \\
\hline X Variable 3 & -12.9404 & 22.444 & 0.5765 & 0.5655 & -57.454 & 31.573 \\
\hline X Variable 4 & 2.94001 & 2.6535 & 1.1079 & 0.2704 & -2.322 & 8.2026 \\
\hline
\end{tabular}

\subsection{FPA Approach}

Characteristics of Flower pollination: Flower pollination algorithm is developed by the idea of flower pollination process. Basically the pollination process carried the pollen from the male parts of a flower to the female part called stigma of a flower [12]. Pollinators can be very diverse. It is estimated that there are at least of two hundred thousand varieties of pollinator exist in nature like insects, bats and birds [13]. There are two types of pollination - Biotic pollination process and Abiotic pollination process.

In Biotic pollination, pollen is carried to the stigma by insects and animals [14] [15] and in Abiotic pollination it occurs via wind or diffusion in water [14] [16]. From survey it is seen that $10 \%$ of pollination is done by the Abiotic pollination process which does not require any pollinators. Pollination can be achieved by two ways. They are selfpollination and cross-pollination. In Cross-pollination process, the pollination can be happened from pollen of a flower of a different plant while in self-pollination the pollination of one flower is transfer from pollen of the same flower or different flowers of the same plant, which often happens when there is no available pollinator [16] [14]. Biotic, cross-pollination may be happened in long distance. Bees, bats, birds and flies are mostly used as pollinators which are able to fly a long distance. So, these pollinators are considered as the carrier of the global pollination [11] [15]. Xin-She Yang describes this flower constancy and pollinator behavior in the pollination process into the following four rules [13]:

1. Biotic and cross-pollination is considered as global pollination process with pollen-carrying pollinators performing L'evy flights.

2. Abiotic and self-pollination both are considered as local pollination.

3. Flower constancy can be considered as the reproduction probability is proportional to the similarity of two flowers involved.

4. Local pollination and global pollination is controlled by a switch probability $p \in[0,1]$. Besides the physical proximity and other factors like wind and water, local pollination can have a significant fraction $\mathrm{p}$ in the overall pollination process [17].

\subsubsection{Global pollination \& local pollination}

Global pollination process and Local pollination process are two key steps in Flower pollination algorithm [13]. In global pollination process, flower pollens are carried by pollinators. These pollens may travel over a long distance because pollinators can often fly and move in longer range. This global pollination can be represented mathematically as

$X_{i}^{t+1}=X_{i}^{t}+L(\lambda) \gamma\left(X_{i}^{t}-g^{*}\right)$

Here $\mathrm{X}_{\mathrm{i}}^{\mathrm{t}}$ is the pollen $\mathrm{X}_{\mathrm{i}}$ or solution vector at iteration $t$, and $\mathrm{g} *$ is the current best solution found among all solutions at the current iteration. Here $\lambda$ is a scaling factor to control the step size. Hence, parameter $\mathrm{L}(\lambda)$ is also the step size which corresponds to the strength of the pollination [11] [13] [17]. Since pollinators can be travelled over a long distance with different distance steps. Here, L'evy flight can be used to imitate this travelling characteristic [16]. Assuming L $>0$ fom a L'evy distribution.

$\mathrm{L} \sim \frac{\lambda L(\lambda) \sin \frac{\pi \lambda}{2}}{\Pi} \frac{1}{S^{1+\lambda}} ;\left(\mathrm{S} » S_{0} \gg 0\right)$

Here, $\Gamma(\lambda)$ is the standard gamma function and L'evy distribution is valid for long steps $\mathrm{S}>0$. Therefore, Rule 2 and Rule 3 which are basically for the local pollination can be represented like

$x_{i}^{t+1}=x_{i}^{t}+\varepsilon\left(x_{j}^{t}+x_{k}^{t}\right)$

Here $X_{j}{ }^{t}$ and $X_{k}{ }^{t}$ are pollen from different flowers of the same plant species. The equation imitates flower constancy in limited neighborhoods [11]. Assuming in mathematically if $\mathrm{X}_{\mathrm{j}}^{\mathrm{t}}$ and $\mathrm{X}_{\mathrm{k}}{ }^{\mathrm{t}}$ comes from the same species or selected from the same population, this equivalently becomes a local random walk if a graph can be drawn from a uniform distribution in $[0,1]$.

\subsubsection{Parameters settings}

The parameter which are used in this paper

- Population size: 10 to 25 .

- Probability switch: 0.8

- Maximum interation (maxite): 2000

- Standard gamma function value $\lambda=1.5$

- $\quad$ The local random walk value $(\varepsilon)=(0,1)$ 
- $\quad$ The switch probability value $(\mathrm{p})=(0,1)$

\subsubsection{Operating system}

- Processor: intel (R) core (TM) i3-2350M CPU @ $2.30 \mathrm{GHz}$

- RAM: 4GB

- System type: 32 bit operating system

- Windows edition: Windows 7

\section{RESULT \& PERFORMANCE ANALYSIS}

The objectives are to minimize the flowrate $F$ of experimental process control setup by choosing optimal design variables: the Anemometer flow sensor output $\mathrm{x}(1)$, pipe diameter $x(2)$, liquid conductivity $x(3)$ and the liquid viscosity $\mathrm{x}(4)$. This objective design problem can be written as :

Object $F=\left(0.350099 * 10^{\wedge}-3\right) *\left(x(1)^{\wedge} 14.20\right) *\left(x(2)^{\wedge}-\right.$

$4.37947) *\left(x(3)^{\wedge}-12.94\right) *\left(x(4)^{\wedge} 2.940\right.$

It is worth to pointing out the minimum value of the objective function. In this paper FPA has to be extended in combination with constraint handling techniques to deal with mixed integer problems efficiently under the simplest branchand -bound method utilized here.

\subsection{Verification}

Matlab code execute for solving the nonlinear equation in FPA, we get the co efficient of $x(1), x(2), x(3), x(4) \&$ e

$y=a x(1)+b x(2)+c x(3)+d x(4)+e$

co efficient: $1.6563 \quad 0.6446 \quad 9.9035 \quad-0.1291 \quad 50$

and total error is For 5.3291e-05(fmin) difference between the predicted $\&$ the optimized output.

Table 5. Percentage of contributions

\begin{tabular}{|l|l|l|l|l|}
\hline Parameters & $\begin{array}{l}\text { Sensor } \\
\text { output }\end{array}$ & Diameter & Conductivity & Viscosity \\
\hline Percentage & 5.375 & 0.046 & 29.72 & 64.85 \\
\hline
\end{tabular}

\section{CONCLUSION}

By using Flower Pollination Alogorithm method and ANOVA we obtained a significant different result of optimum conditions. The following are the co efficient of the parameters in order of significantly affecting the liquid flow process: sensor output $\mathrm{x}(1)$, pipe diameter $\mathrm{x}(2)$, liquid conductivity $\mathrm{x}(3)$ $\&$ liquid viscosity $\mathrm{x}(4)$ are $(14.20,-4.37947,-12.94,2.94 \&$ $\left.350099 * 10^{\wedge}-3\right)$ in ANOVA \& new set of value coefficient in FPA is $(1.6563,0.6446,9.9035,-0.1291 \& 50)$. Both the cases the predicted result is compared to the experiments, verified. Therefore the obtained optimum conditions are proven to be effective. The optimization process that performed by FPA method brings out the best conditions to be used in a liquid flow process that could actualize a friendly environmental process due to the total least error. From table.4 statistical results (at a 95\% confidence level) show that the sensor output, pipe diameter, conductivity and viscosity affect the Flow rate by $5.375 \%, 0.046 \%, 29.72 \% \& 64.85 \%$ in the Anemometer based liquid flow process control system respectively.

\section{REFERENCES}

[1] Kalogirou S. (2003). artificial intelligent for the modelling and control of combustion processes: a review. Progress in Energy and Combustion Science 29(6): 515566.

[2] Isermann R, Muller N. (2003). Design of computer controlled combustion engines. Mechatronics 13(10): 1067-1089.

[3] Hafner M, Schuler M, Nelles O, Isermann R. (2000). Fast neural netwroks for diesel engine control design. Control Engineering Practice 8(11): 1211-1221.

[4] Ashhab MS. (2004). A combination of neural net modelling and constrained optimization towards inverse control. $4^{\text {th }}$ IASTED International Conference on Modelling, Simulation and Optimization, Kauai-USA 66-71.

[5] Slanvetpan T, Barat R, Stevens J. (2003). Process control of a laboratry combustor using artificial neural networks, Comput. Chem. Eng. 27(11): 1605-1616.

[6] Noeres C, Dadhe K, Gesthuisen R, Ngell S, Gorak A. (2004). Model based design ,control and optimization of catalytic distillation process. Chemical Engineering Process 43(3): 421-434.

[7] Datta A, Hareesh M, Kalra PK, Boom R. (1994). Adaptive Neural Net (ANN) models for desulphurization of hot metal ans steel. Steel Research International 65(11): 466-471.

[8] Karniel A, Meir R, Inbar GF (2001). Best estimated inverse versus inverse of the best estimator, Neural Networks 14(9): 1153-1159.

[9] Al-salaymeh (2001). Flow velocity and Volume flow rate sensor with a wide Bandwidth. PhD Dissertation. Technischen Fakultatder universitat Erlangen-Numberg.

[10] Pijush D, Asok K. (2017). Intelligent calibration technique using optimized fuzzy logic controller for controller for ultrasonic flow sensor. Mathematical Modelling of Engineering Problems 4(2): 91-94.

[11] Yang XS, Mehmet K, He XS. (2013). Multi-objective Flower Algorithm for Optimization. International Conference on Computational Science, ICCS 2013.

[12] Walker M. (2009). How flowers conquered the world, BBC Earth News.

[13] Yang XS. (2012). Flower pollination algorithm for global optimization. Unconventional Computation and Natural Computation, Lecture Notes in Computer Science 7445: 240-249.

[14] Gaganpreet K, Dr. DS. (2012). Pollination based optimization or color image segmentation. International Journal of Computer Engineering and Technology (IJCET) 3(2): 407-414.

[15] KS. (2012). Pollination based optimization. 6th International Multi Conference on Intelligent Systems, Sustainable, New and Renewable Energy Technology and Nanotechnology (IISN2012).

[16] Waser N. (1986). Flower constancy: definition, cause and measurement. The American Naturalist 127(5): 593603. 
[17] Osama AR, Mohamed AB, Ibrahim EH. (2014). A novel hybrid flower pollination algorithm with chaotic harmony search for solving sudoku puzzles. International Journal of Engineering Trends and Technology (IJETT) 7(3): 126-132.

[18] Yang XS. (2010). Engineering optimization: an introduction with metaheuristic application. Wiley.

[19] Abbass HA, Sarker R. (2002). The Pareto diffential evolution algorithm. Int. J. Artificial Intelligence Tools 11(4): 531-552.

[20] Yang XS. Nature-inspired Metaheuristic Algorithms. Luniver Press.

[21] Deb K. (2001). Multi-objective Optimization Using Evolutionary Algorithms. New York: John Wiley \& Sons.

[22] Wang G, Guo L. (2013). A novel hybrid bat algorithm with harmony search for global numerical optimization. Journal of Applied Mathematics 2013: 21.

[23] Yang XS. (2010). A new metaheuristic bat-inspired algorithm, nature inspired cooperative strategies for optimization (NISCO 2010). Springer 284: 65-74.

[24] Khan K, Sahai A. (2012). A comparison of BA, GA, PSO, BP and LM for training feed forward neural networks in e-learning context. I.J. Intelligent Systems and Applications 23-29.

[25] Wasiulkabir M, Sakib N Sakib, Syed MRC, Shafiul Alam M. (2014). A novel adaptive bat algorithm to control explorations and exploitations for continuous optimization problems. International Journal of Computer Applications 94(13).

[26] Rekaby A. (2013). Directed Artificial Bat Algorithm (DABA) a new bio-inspired algorithm. International Conference on Advances in Computing, Communications and Informatics (ICACCI), Cairo.

[27] Selim Y, Ecir UK. (2013). Improved Bat Algorithm (IBA) on continuous optimization problems. Lecture Notes on Software Engineering 1(3): 279-283.

[28] Huang GQ, Zhao W J, Lu QQ. (2013). Bat algorithm with global convergence for solving large scale optimization problem. Application Research of Computers 30(3): 1-10.

[29] Asghar A, Abdul Raman AA, Wan Daud WMA. (2014). A comparison of central composite design and taguchi method for optimizing fenton process. The Scientific World Journal 2014.

[30] Bremhost K, Graham L.J.W. (1990). A fully compensated hot/cold wire anemometer system for unsteady flow velocity and temperature measurement. Measurement Science \& Technology 1(5).

[31] Moh'd S, Ahmed Al S. (2006). Optimization of hot wire thermal flow sensor based on neural net model. Applied Thermal Engineering 26(8-9): 948-955.

[32] Pijush D, Asok K. (2017). Intelligent calibration technique using optimized fuzzy logic controller for ultrasonic flow sensor. Mathematical Modelling of
Engineering Problems 4(2): 91-94.

[33] Satish Chandra B, Samik M. (2012). Study of a simplelinearization technique of a $p-n$ junction type anemometer flow sensor. IEEE Transaction Instrumentation and Measurement 61(9): 545-2552.

\section{MATLAB CODE FOR TEST}

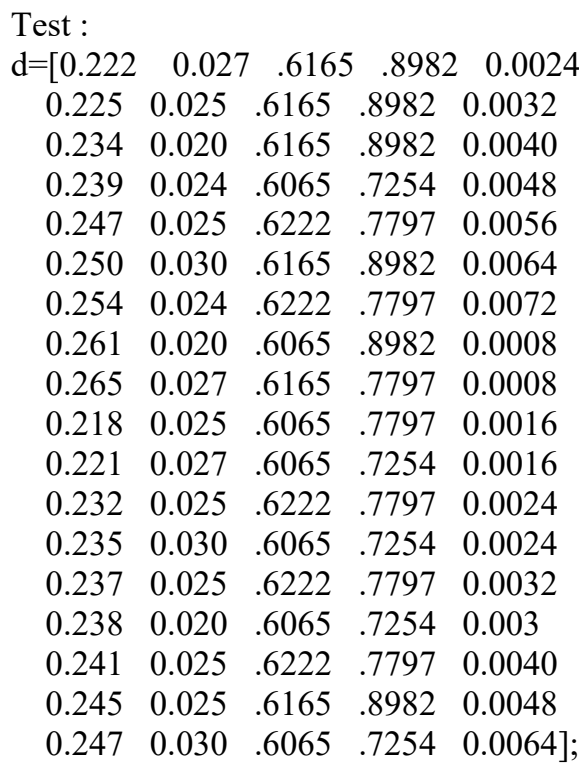

For $=1: 18$

$\%$ sum(i1) $=\mathrm{d}(\mathrm{i} 1,1) * \mathrm{u}(1)+\mathrm{d}(\mathrm{i} 1,2) * \mathrm{u}(2)+\mathrm{d}(\mathrm{i} 1,3) * \mathrm{u}(3)+$

$\mathrm{d}(\mathrm{i} 1,4) * \mathrm{u}(4)+\mathrm{u}(5)$

sum1 $(\mathrm{i} 1)=\left(\mathrm{d}(\mathrm{i} 1,1)^{\wedge} \mathrm{u}(1)\right)^{*}\left(\mathrm{~d}(\mathrm{i} 1,2)^{\wedge} \mathrm{u}(2)\right)^{*}\left(\mathrm{~d}(\mathrm{i} 1,3)^{\wedge} \mathrm{u}(3)\right)^{*}(\mathrm{~d}(\mathrm{i} 1$, $\left.4)^{\wedge} \mathrm{u}(4)\right)^{*} \mathrm{u}(5)$;

end;sum 1

sum $=0$; for

$\mathrm{i} 1=1: 18 \% \mathrm{z} 2=\mathrm{d}(\mathrm{i} 1,1) * \mathrm{u}(1)+\mathrm{d}(\mathrm{i} 1,2) * \mathrm{u}(2)+\mathrm{d}(\mathrm{i} 1,3) * \mathrm{u}(3)+\mathrm{d}(\mathrm{i} 1$, $4) * u(4)+u(5)$

$\mathrm{z} 2=\left(\mathrm{d}(\mathrm{i} 1,1)^{\wedge} \mathrm{u}(1)\right)^{*}\left(\mathrm{~d}(\mathrm{i} 1,2)^{\wedge} \mathrm{u}(2)\right)^{*}\left(\mathrm{~d}(\mathrm{i} 1,3)^{\wedge} \mathrm{u}(3)\right)^{*}\left(\mathrm{~d}(\mathrm{i} 1,4)^{\wedge} \mathrm{u}(4)\right.$

)$^{*} \mathrm{u}(5)$;

sum $=$ sum $+(d(\text { i1 }, 5)-z 2)^{\wedge} 2$

end;

$\mathrm{z}=$ sum

for ANOVA

coefficint :

$14.20 \quad-4.37947 \quad-12.94 \quad 2.94 \quad 0.350099^{*} 10^{\wedge}-3$

Total error : $6.5656 \mathrm{e}-04(\mathrm{fmin})$

For FPA :

coefficient : $1.6563 \quad 0.6446 \quad 9.9035 \quad-0.1291 \quad 50$

Total error: 5.3291e-05(fmin) 